\title{
Congenital infections in Hong Kong: beyond TORCH
}

\author{
KL Hon *, Karen KY Leung, Alexander KC Leung, Elim Man, Patrick Ip
}

\section{A B S T R A C T}

Congenital infections refer to a group of perinatal infections that are caused by pathogens transmitted from mother to child during pregnancy (transplacentally) or delivery (peripartum) which may have similar clinical presentations, including rash and ocular findings. TORCH is the acronym that covers these infections (toxoplasmosis, other [syphilis], rubella, cytomegalovirus, herpes simplex virus). Other important causes of intrauterine/ perinatal infection include human immunodeficiency virus, varicella-zoster virus, Treponema pallidum, Zika virus, and parvovirus B19. This overview aims to describe various congenital infections beyond TORCH with a Hong Kong perspective. Intrauterine and perinatal infections are a major cause of in utero death and neonatal mortality, and an important contributor to childhood morbidity. A high index of suspicion for congenital infections and awareness of the prominent features of the most common congenital infections can help to facilitate early diagnosis, tailor appropriate diagnostic evaluation, and initiate appropriate early treatment. Intrauterine

This article was published on $24 \mathrm{Jul}$ 2020 at www.hkmj.org.

infections should be suspected in newborns with

\section{Introduction}

Congenital infections are those that can cross the placenta and damage the fetus in utero or transmit to the infant during delivery in the peripartum period, resulting in neonatal infection. ${ }^{1}$ Congenital infections also account for $2 \%$ to $3 \%$ of all congenital anomalies apart from miscarriage, stillbirth, and neonatal deaths and are a significant cause of childhood morbidity. ${ }^{2-4}$ Immunologist Andres Nahmias first used the acronym ToRCH in 1971 to describe perinatal infections associated with toxoplasma (To), rubella (R), cytomegalovirus $(\mathrm{C})$, and herpes simplex virus $(\mathrm{H}) .^{5}$ Subsequently, the ' $\mathrm{O}$ ' in TORCH has been broadened and now stands for 'Others', including the following pathogens: syphilis, parvovirus B19, coxsackievirus, listeriosis, hepatitis virus, varicella-zoster virus (VZV), Trypanosoma cruzi, enterovirus, human immunodeficiency virus (HIV), and the latest addition, Zika virus (ZIKV). ${ }^{1,4}$

Congenital infections have remained a major global health issue, those in developing countries are particularly vulnerable. Congenital infections can lead to significant consequences, such as severe disabilities or even the death of the fetus. We recently overviewed "TORCH" in detail, ${ }^{6}$ and this overview clinical features including microcephaly, seizures, cataract, hearing loss, congenital heart disease, hepatosplenomegaly, small for gestational age, and/or rash. Primary prevention of maternal infections during pregnancy is key to the prevention of congenital infection, and resources (if available) should focus on public health promotion and pre-marital counselling.

\begin{tabular}{l} 
Hong Kong Med J 2020;26:323-30 \\
\hline https://doi.org/10.12809/hkmj208398 \\
${ }^{1}$ KL Hon *, MB, BS, MD \\
${ }^{1}$ KKY Leung, MB, BS, MRCPCH \\
${ }^{2}$ AKC Leung, FRCP (UK), FRCPCH \\
${ }^{1}$ E Man, MB, BS, MRCPCH \\
${ }^{3}$ P Ip, FRCPCH, MPH \\
${ }^{1}$ Department of Paediatrics and Adolescent Medicine, The Hong Kong \\
Children's Hospital, Hong Kong \\
${ }^{2}$ Department of Pediatrics, The University of Calgary, and The Alberta \\
Children's Hospital, Calgary, Alberta, Canada \\
${ }^{3}$ Department of Paediatrics and Adolescent Medicine, The University of \\
Hong Kong, Hong Kong \\
* Corresponding author: ehon@cuhk.edu.hk
\end{tabular}

focuses on the following congenital infections beyond TORCH, namely, HIV, VZV, ZIKV, and parvovirus B19. References were searched using key terms ("congenital infection") and ("Hong Kong") or ("Zika") and ("Hong Kong") in PubMed, limited to 'human', with no filters on article type or publication time. Discussion is based on but not limited to the search results.

\section{Congenital human immunodeficiency virus infection}

The HIV strains HIV-1 and HIV-2 are cytopathic lentiviruses belonging to the family Retroviridae. ${ }^{7}$ Paediatric HIV infection remains a significant global health issue: the Joint United Nations Programme on HIV/AIDS reported that an estimated 3.1 million children were living with HIV globally. ${ }^{8}$ Congenital infection with HIV can occur via the transplacental route to the developing fetus. Over $90 \%$ of HIV infections in children worldwide are caused by MTCT, which is one of the three general modes of HIV transmission. ${ }^{9}$

The first case of HIV infection in Hong Kong was reported in 1984. The Department of Health has had a voluntary and anonymous HIV/AIDS 


\section{香港TORCH以外的先天性感染概述}

韓錦倫、梁嘉恩、梁國柱、文爾琳、葉柏強

先天性感染指一組圍產期感染, 於懷孕（胎盤）或分娩（圍產期） 期間從母親傳給孩子的病原體引起。這些病原體可能具有類似臨床表 現, 包括皮疹和眼部表徵。TORCH是涵蓋弓形蟲（ T ）、其他包括梅 毒 $(O)$ ）德國麻疹 $(R)$ 、巨細胞病毒 $(C)$ 和單純皰疹病毒 $(H)$ 感染的首字母縮寫。宮內和圍產期感染的其他重要因素包括HIV 水痘帶狀皰疹病毒、梅毒、寨卡病毒和細小病毒B19。本文概述香港 TORCH以外的各種先天性感染。宮內和圍產期感染是子宮內死亡和 新生兒死亡的主因, 也是導致兒童發病的重要因素。對先天性感染提 高警覺以及加強對最常見先天性感染顯著特徵的認識有助早期診斷、 制定合適的診斷評估和及早治療。當出現以下臨床特徵時應懷疑新生 兒宮內感染, 包括小頭畸形、癲病、白內障、聽力下降、先天性心藏 病、肝脾腫大、胎齡細小及皮疹。妊娠期母親感染的一級預防是預防 先天性感染的關鍵, 並在資源許可的情況下應集中推廣公共衛生和婚 前諮詢。 size for date, failure to thrive, developmental delay, cardiomyopathy, encephalopathy, and nephropathy can also be seen. ${ }^{12.13}$ Recurrent VZV and herpes simplex virus infections, severe molluscum contagiosum, chronic fungal infections, and atopic dermatitis are common skin manifestations. ${ }^{14,15}$ Preconception counselling should be provided to women with HIV of childbearing age to discuss their reproductive desires. Promotion of safe sex and information about effective and appropriate contraceptive methods should be offered to avoid unplanned pregnancy. Alternatively, if pregnancy is desired, facilitating planned pregnancy is equally important, as HIV-positive couples could benefit from assisted reproduction. ${ }^{9}$

To effectively prevent MTCT of HIV during pregnancy, the mother should receive antiretroviral (ARV) therapy during the antepartum, intrapartum, and postnatal periods. The treatment should be individualised with the goal of virologic suppression to undetectable levels. ${ }^{7}$ Intrapartum zidovudine is recommended if the pregnant woman with HIV presents late and has received no prior ARV therapy or if the HIV viral load is high ( $>50$ copies $/ \mathrm{mL}$ ) close to delivery. ${ }^{16}$ Caesarean section is indicated if the mother's viral load is $>1000$ copies $/ \mathrm{mL}$. For mothers with HIV infection who proceed to vaginal delivery, prolonged rupture of membranes, invasive fetal monitoring, and instrumental delivery should be avoided to reduce the risk of MTCT. ${ }^{16}$

A paediatrician who is experienced in HIV management should be involved in the infant's antenatal and post-delivery care. The exposed infant should begin with ARV prophylaxis soon after birth, preferably within 12 hours. If the mother has received ARV therapy during pregnancy, neonatal prophylaxis consists of zidovudine for 6 weeks after birth until HIV-negative status is confirmed. If the mother did not receive any ARV regimen or her HIV RNA level is high $(\geq 1000$ copies $/ \mathrm{mL}$ ) or unknown, neonatal prophylaxis to lower the rate of MTCT should consist of a two- or three-drug ARV regimen. ${ }^{7}$ Breastfeeding should be avoided if possible, as HIV transmission by breastfeeding accounts for one third to half of MTCT of HIV worldwide. ${ }^{717}$ Studies in the pre-ARV therapy era reported the postnatal transmission rate to be as high as $32 \%$ at 6 months. ${ }^{18}$ A Universal Antenatal HIV Testing Programme with an opt-out approach has been implemented in Hong Kong since 2001. The programme is widely accepted by antenatal women, and the opt-out rate has been $<3 \% .{ }^{9}$ However, despite the high coverage of $\geq 98 \%$, five infants whose mothers were screened as negative by the Universal Antenatal HIV Testing Programme during the early antenatal period were found to be HIV-positive from 2009 to 2015. Hence, it was suspected the MTCT in those cases occurred in late pregnancy. Unprotected sex during 
pregnancy was the common risk factor among those cases, which reinforces the importance of advising protected sex during pregnancy. ${ }^{10,16}$ A second HIV test is recommended in the third trimester for patients at risk of HIV infection or if there are symptoms and signs compatible with acute HIV infection. ${ }^{16}$ If the mother's HIV status is unknown at delivery, a highly sensitive and specific rapid HIV test should be performed. ${ }^{19}$ Prophylactic interventions against MTCT should be implemented if the result is positive. ${ }^{16}$ With the implementation of universal prenatal screening, effective ARV therapy for all pregnant women with HIV, scheduled Caesarean delivery for cases with high viral load, ARV for infants, and avoidance of breastfeeding, the rate of MTCT is $<1 \% .{ }^{20,21}$ This highlights the importance of universal screening and antenatal care that vertical transmission of HIV is potentially preventable when these interventions are implemented. Management of HIV in mothers and newborns has improved outcomes over the past 20 years.

\section{Congenital varicella syndrome}

Varicella-zoster virus is a member of the herpesvirus family. Pregnant women are several times more likely to develop fatal VZV than non-pregnant ones. Although rare, the fetus is at high risk of congenital varicella syndrome (CVS) if the mother is infected, and the neonate is at high risk of a severe or fatal form of VZV. ${ }^{22}$

Varicella is the most frequently reported notifiable disease in Hong Kong. ${ }^{23}$ More than 95\% of the population not vaccinated against VZV has been infected, mostly before 20 years of age. ${ }^{24}$ Approximately 95\% of pregnant women were found to be seropositive for VZV in a 2009 study. ${ }^{25}$ With the vast majority of the population immune to VZV at childbearing age, the risk of primary infection during pregnancy (and thus the risk of congenital VZV infection) is relatively low. A worldwide systemic review of the literature from 1947 to 2013 indicated that there were only 130 reported cases of congenital VZV infection in that period. ${ }^{26}$ Only two cases of neonatal VZV infection were reported in Hong Kong from 2008 to $2010 .{ }^{27}$ Transmission of VZV can occur via multiple routes, including infected respiratory tract secretions, direct contact with infectious vesicular fluid from moist lesions, and occasionally through airborne spread, entering the host through the conjunctiva or the mucosal surface of the upper respiratory tract., ${ }^{728}$ Varicella is highly contagious from 1 to 2 days before the onset of the rash, until all lesions are crusted. ${ }^{7,28}$ Transplacental passage of VZV from maternal infection can result in congenital or neonatal VZV infection. ${ }^{7,28}$ The risk of vertical transmission reaches $25 \%$ if maternal primary infection occurs during the first or second trimesters, with around $12 \%$ risk of congenital anomalies among newborns of mothers who were infected during that period. ${ }^{29}$ The rate of vertical transmission reaches up to $50 \%$ when maternal VZV infection occurs within 1 to 4 weeks before delivery, with $23 \%$ developing neonatal VZV infection..$^{30,31}$

Fetal VZV infection in utero can result in a range of adverse sequelae. Low birth weight is universal, and intrauterine growth restriction is observed in around $23 \%$ of cases. ${ }^{30}$ Further, approximately $20 \%$ of infants with in utero VZV infection develop neonatal or infantile herpes zoster. ${ }^{30}$ Congenital anomalies resulting from congenital VZV infection are known collectively as CVS, which is expected in approximately $12 \%$ of infected fetuses. ${ }^{29}$ Maternal infection within the first 20 weeks of gestation is responsible for most cases of CVS, with newborns of mothers infected between the 7th and 20th weeks having the highest risk. ${ }^{28}$ No cases of CVS have been reported when maternal varicella infection occurs after the 28 th week of gestation. ${ }^{32}$ The clinical manifestations of CVS include cutaneous scars in a dermatomal distribution, limb hypoplasia, microcephaly, cortical atrophy, hydrocephaly, mental retardation, microphthalmia, chorioretinitis, cataracts, muscle hypoplasia, developmental delay, and anomalies of the cardiovascular system, gastrointestinal tract, and genitourinary tract. ${ }^{7,30,33,34}$ During the first few months of life, CVS has a $30 \%$ mortality rate..$^{30}$ Neonatal VZV infection can result from transplacental passage of VZV and ascending or postnatal infections. If $\mathrm{VZV}$ infection occurs during the first 10 to 12 days of life, it is often the result of intrauterine transmission, whereas VZV with later onset is usually acquired postnatally. ${ }^{27,30}$ Appropriate treatment with varicella-zoster immunoglobulin (VZIG) and antivirals has reduced the mortality rate of neonatal VZV to $7 \% .^{31}$

Prenatal diagnosis of CVS is often based on detection of VZV DNA in the amniotic fluid or fetal blood by PCR. In addition, ultrasonography findings consistent with CVS, such as microcephaly, limb deformities, polyhydramnios, soft tissue calcification, and intrauterine growth restriction can be diagnostic when there is a history of maternal VZV infection. ${ }^{19,30}$ An ultrasound examination should be performed at least 5 weeks after the onset of rash in the mother. ${ }^{30}$

Congenital varicella syndrome is diagnosed postnatally when there is history of maternal VZV during pregnancy, in the presence of skin lesions distributed along dermatome(s), and in the presence of other clinical manifestations consistent with CVS or neonatal seizures. ${ }^{35}$ The presence of VZV DNA in the newborn, detection of immunoglobulin $M$ antibodies against VZV in the cord blood or fetal blood, immunoglobulin $\mathrm{G}$ antibodies against VZV persisting longer than the first 7 months of life, or development of herpes zoster during early infancy 
indicate intrauterine VZV infection regardless of CVS development. ${ }^{30}$

Oral acyclovir with or without VZIG is recommended for pregnant women infected with varicella, as it can shorten the duration of fever and reduce the symptoms of varicella when antiviral therapy is initiated within 24 hours after the onset of rash. ${ }^{28,36}$ Acyclovir is effective at lowering the morbidity and mortality rates of both the fetus and the mother when administered within 24 and up to 72 hours of the onset of rash, and VZIG has been reported to lower the incidence and severity of varicella. ${ }^{30} \mathrm{~A} 10$-day course of intravenous acyclovir is effective in neonates affected by varicella and complications of CVS. ${ }^{7}$ Prophylactic use of VZIG is also possible in susceptible pregnant mothers exposed to VZV within 72 and up to 96 hours of exposure but is not effective after clinical signs have appeared. ${ }^{37}$ Administration of VZIG in neonates should occur within 10 days of initial exposure for prophylaxis if the mother has perinatal varicella rash and absence of antibodies against VZV in the mother or the neonate. ${ }^{7}$ In women of childbearing age who are not immune to VZV, vaccination after exposure can effectively prevent infection, especially when administered within 3 days of exposure. ${ }^{38}$

Vaccination against VZV was incorporated into the Hong Kong Childhood Immunisation Programme (HKCIP) in 2014. ${ }^{39}$ For eligible children born on or after 1 January 2013, the first vaccination is given at age 12 months, and the second dose (at around age 6-7 years) in primary one, given as part of the measles mumps, rubella, and varicella vaccine. Before being incorporated into the HKCIP, a varicella vaccine was available on the private market. A local study conducted in 2012 found that the parent-reported VZV vaccination uptake was $65 \%$ in kindergarten students, and the rate was $69 \%$ of preschool and schoolchildren in another study conducted in 2013. ${ }^{40,41}$ The vaccination rate is expected to rise after incorporation of the varicella vaccine into the HKCIP, as coverage of all other vaccines in the HKCIP has been maintained at over $95 \%$. Because the incidence of varicella in younger children is likely to drop because of increased immunisation, the effects of the vaccination on incidence during pregnancy remain to be elucidated.

\section{Congenital Zika virus infection}

Zika virus is a neurotropic flavivirus that particularly infects neural progenitor cells. Approximately 80\% of ZIKV infection is asymptomatic. ${ }^{42}$ Symptomatic infections can be categorised as either Zika fever or congenital Zika syndrome. Zika fever is a relatively mild disease that presents with low-grade fever, generalised maculopapular rash, non-purulent conjunctivitis, myalgia, and arthralgia of the small joints of the hands and feet, although more severe complications, including Guillain-Barre syndrome, seem to be associated as well. ${ }^{42}$ The disease is usually self-limiting and resolves within 3 to 7 days. ${ }^{42}$ Zika virus infection during pregnancy is associated with a higher rate of fetal loss, including stillbirths. In addition, serious sequelae can be observed in infants with congenital Zika syndrome, making it an important public health concern in some areas.

Congenital Zika syndrome raised international public health concern after the increase in cases of congenital microcephaly in neonates in October 2015 following an outbreak of ZIKV infection in Brazil. Fortunately, since ZIKV infection became a notifiable disease in February 2016, the number of cases in Hong Kong has remained low, with only two cases in 2016 and one case in 2017..$^{23}$ Therefore, the risk of congenital Zika syndrome is extremely low in Hong Kong.

Transmission of ZIKV primarily occurs via infected Aedes mosquitoes. It may also be transmitted through sexual contact, blood transfusion, and organ transplantation. ${ }^{43,44}$ Vertical transmission through the placenta is a major concern because of the resulting congenital Zika syndrome. A report by the United States Zika Pregnancy Registry found congenital defects in $10 \%$ of 250 cases with laboratory-confirmed ZIKV infection during pregnancy. ${ }^{45,46}$

Neurological findings seen in congenital Zika syndrome include microcephaly, cutis gyrata, ventriculomegaly, subcortical calcifications, polymalformative syndrome (including craniofacial disproportion and craniosynostosis), brainstem dysfunction, developmental delay, sensorineural hearing loss, seizures, marked hypertonia, hyperreflexia, and dysphagia. ${ }^{45,47}$ Ophthalmological findings include cataracts, asymmetrical ocular size, intraocular calcifications, macular abnormalities (pigmentary retinal mottling, chorioretinal atrophy/scarring), optic nerve abnormalities (optic nerve hypoplasia, increased cup-to-disk ratio), subretinal haemorrhage, coloboma, microcornea, microphthalmia, cataracts, glaucoma, and lens subluxation. ${ }^{48-50}$ Congenital heart disease occurs in $10 \%$ to $15 \%$ of cases. ${ }^{51}$ Although the full spectrum of the syndrome has not been completely delineated, a review study identified some characteristic features of congenital Zika syndrome, including severe microcephaly with partially collapsed skull, thin cerebral cortices with subcortical calcifications, macular scanning, focal pigmentary retinal mottling, congenital limb contractures, and marked early hypertonia with signs of extrapyramidal involvement..$^{52}$ In one study of 117 liveborn infants born to pregnant women with confirmed ZIKV infection, the overall rate of functional and structural abnormalities was $42 \% .^{53}$ 
Definitive diagnosis of congenital ZIKV infection can only be established within the first few days of life by detecting ZIKV RNA in the serum, urine, or cerebrospinal fluid via a real-time reverse transcription PCR nucleic acid test. ${ }^{54}$ Detection of immunoglobulin $\mathrm{M}$ antibodies against ZIKV in the serum or CSF by enzyme-linked immunosorbent assay can support the diagnosis..$^{54}$ Because there is currently no effective antiviral treatment for ZIKV infection, supportive treatment is mainly offered to manage the complications of congenital Zika syndrome. Continuous healthcare support and referral to developmental specialists to monitor the condition are recommended. ${ }^{54}$

As no vaccine against ZIKV is currently available, avoidance of ZIKV infection by personal protection against mosquito bites and vector control remains the most effective means to prevent congenital Zika syndrome. Pregnant mothers should avoid travelling to places with known ZIKV transmission by mosquitoes and maintain mosquito prevention practices, such as removing mosquitoes' breeding grounds, wearing long-sleeved clothing, and using mosquito repellents. Protective measures against possible sexual transmission should also be adopted to minimise the risk of ZIKV infection during pregnancy.

\section{Parvovirus B19 infection}

Parvovirus B19 is the only pathogenic human parvovirus. In Hong Kong, the prevalence of antibodies to the B19 virus has been reported as $20 \%$, which is much lower than the corresponding value for the Western population, where $>60 \%$ of adults have been reported to be seropositive. ${ }^{55,56}$ The epidemiology of parvovirus B19 infection during pregnancy in Hong Kong is unknown, but it is likely to have low prevalence in light of the low population prevalence rate..$^{57}$ Only three local case reports of hydrops fetalis due to parvovirus B19 were found in the literature..$^{57-59}$

Parvovirus B19 infection in adults is usually asymptomatic. ${ }^{60}$ Parvovirus infection in pregnant women is associated with hydrops fetalis because it causes severe fetal anaemia, sometimes leading to miscarriage or stillbirth. ${ }^{60-62}$ This is caused by a combination of haemolysis of red blood cells and the virus directly negatively affecting red blood cell precursors in the bone marrow. The risk of fetal loss is about $10 \%$ if infection occurs before week 20 of pregnancy (especially between weeks 14 and 20) but minimal after then. In contrast, parvovirus B19 infection during the second trimester is more commonly associated with hydrops fetalis or fetal loss. If the fetus does not develop any of these acute complications, or if intrauterine blood transfusion is successful in saving the fetus, the risk to the fetus presented by chronic parvovirus B19 infection is negligible.

Knowledge of the mother's parvovirus B19 immune status could allow her to avoid contact with individuals suspected or known to have ongoing parvovirus B19 infection. However, antenatal immunity testing is not currently recommended, as there is no effective means to prevent infection, no specific therapy, and no vaccines available. Thus, testing may increase maternal anxiety and fear without proven benefit.

The best approach would be to recommend that all pregnant women avoid contact with children who currently have symptoms of parvovirus B19 infection. However, if a pregnant woman is exposed to parvovirus $\mathrm{B} 19$, serological testing should be performed as soon as possible to determine whether she should be monitored for seroconversion..$^{63}$ If the results are suggestive of an acute parvovirus B19 infection, the fetus should be monitored by regular ultrasound assessment for signs of fetal hydrops and fetal anaemia. The peak systolic velocity of the fetal middle cerebral artery is an accurate predictor of fetal anaemia, ${ }^{63}$ and intrauterine blood transfusions can be considered in severe cases. Although some case reports have suggested that intrauterine parvovirus B19 infection caused developmental abnormalities in childhood, epidemiologic studies have not supported this association. ${ }^{64,65}$ The bulk of the available data suggest that parvovirus B19 is not teratogenic. ${ }^{19,61}$ No human vaccine against parvovirus B19 has been approved to date..$^{66,67}$

\section{Conclusion}

Although Hong Kong still has relatively low rates of congenital infections among countries in more developed regions despite being densely populated, it is important to remain vigilant against any possible infections during pregnancy, which may lead to severe morbidities and mortality of the fetus or infant.

The antenatal screening programme in Hong Kong is tailored to the local epidemiology of infectious and hereditary diseases, aiming to detect significant diseases that are potentially damaging to the fetus as early as possible. At present, the congenital infections for which the programme screens include rubella, hepatitis B, syphilis, and HIV, and the hereditary diseases screened for are thalassemia and Down syndrome.

Health authorities (eg, the Centre for Health Protection), obstetricians, and paediatricians should collaborate to establish a central congenital infection disease registry. This registry could be used for disease surveillance and monitoring of the outcomes of congenital infections. These results would be useful for detection of disease clusters and determination of their prevalence, morbidity, and mortality. Such a registry would help to estimate 
the burden of these congenital infections on the healthcare system and guide resource allocation.

The data for such a registry could be captured from the notifiable disease database and laboratory surveillance of antenatal blood samples. Congenital rubella syndrome and Zika virus are notifiable diseases in Hong Kong, as their risk of transmission is high, outbreaks of these diseases can impose a significant risk to the community, and public health measures can be implemented if an outbreak is detected early. In terms of other congenital infections, the universal antenatal screening programme in Hong Kong should be able to identify most cases of congenital syphilis, rubella, and HIV. If recourses are available, health authorities can consider including congenital HIV and congenital syphilis as notifiable diseases. At present, the Hong Kong Department of Health has a surveillance programme intended to detect most congenital HIV and syphilis infections. ${ }^{68}$ Mothers with herpes simplex virus who are symptomatic should present during an antenatal visit. Toxoplasmosis and cytomegalovirus are not part of the antenatal screening programme, but serological tests can be performed if there is suspicion of congenital infection.

A congenital infection registry could act as a platform to provide information for disease surveillance. Public health promotion for primary prevention of maternal infections during pregnancy is the key to avoiding congenital infections.

\section{Author contributions}

Concept or design: KL Hon.

Acquisition of data: KL Hon, KKY Leung.

Analysis or interpretation of data: KL Hon, KKY Leung.

Drafting of the manuscript: KL Hon, KKY Leung.

Critical revision of the manuscript for important intellectual content: All authors.

All authors had full access to the data, contributed to the study, approved the final version for publication, and take responsibility for its accuracy and integrity.

\section{Conflicts of interest}

As an editor of the journal, KL Hon was not involved in the peer review process. Other authors have disclosed no conflicts of interest.

\section{Funding/support}

This research received no specific grant from any funding agency in the public, commercial, or not-for-profit sectors.

\section{References}

1. DeVore NE, Jackson VM, Piening SL. Torch infections. Am J Nurs 1983;83:1660-5.

2. Neu N, Duchon J, Zachariah P. TORCH infections. Clin Perinatol 2015;42:77-103, viii.

3. Stegmann BJ, Carey JC. TORCH infections. Toxoplasmosis, other (syphilis, varicella-zoster, parvovirus B19), rubella, cytomegalovirus (CMV), and herpes infections. Curr Womens Health Rep 2002;2:253-8.

4. Schwartz DA. The origins and emergence of Zika virus, the newest TORCH infection: what's old is new again. Arch Pathol Lab Med 2017;141:18-25.

5. Nahmias AJ, Walls KW, Stewart JA, Herrmann KL, Flynt WJ. The ToRCH complex-perinatal infections associated with toxoplasma and rubella, cytomegol- and herpes simplex viruses. Pediatr Res 1971;5:405-6.

6. Leung KK, Hon KL, Yeung A, Leung AK, Man E. Congenital infections in Hong Kong: an overview of TORCH. Hong Kong Med J 2020;26:127-38.

7. Kimberlin DW, Brady MT, Jackson Mam Long SS, editors. Red Book 2018: Report of the Committee on Infectious Diseases. Itasca: American Academy of Pediatrics; 2018.

8. World Health Organization. Global guidance on criteria and processes for validation: elimination of mother-tochild transmission of HIV and syphilis. 2nd ed. 2017. Available from: https://www.who.int/reproductivehealth/ publications/emtct-hiv-syphilis/en/. Accessed 3 Oct 2019.

9. Wong $\mathrm{KH}$, Chan $\mathrm{KC}$, Bognar FA. An update on HIV and pregnancy. Hong Kong J Gynaecol Obstet Midwifery 2007;7:48-52.

10. Red Ribbon Centre, Centre for Health Protection, Department of Health, Hong Kong SAR Government. Wong CK, Lin WC, Wong KH. Closing the gap of perinatal HIV infection in Hong Kong. Available from: https://www. rrc.gov.hk/research/ab201701.pdf. Accessed 4 Oct 2019.

11. Lilian RR, Kalk E, Bhowan K, et al. Early diagnosis of in utero and intrapartum HIV infection in infants prior to 6 weeks of age. J Clin Microbiol 2012;50:2373-7.

12. Hegde HR, Leung AK, Robson WL. Anergy and AIDS. J Acquir Immune Defic Syndr 1988;4:1004.

13. Hon KL, Leung TF, Yau YS. Pneumonitis and extreme failure to thrive. Hong Kong Med J 2014;20:556.e1-3.

14. Leung AK, Barankin B, Hon KL. Molluscum contagiosum: an update. Recent Pat Inflamm Allergy Drug Discov 2017;11:22-31.

15. Leung AK, Hon KL, Robson WL. Atopic dermatitis. Adv Pediatr 2007;54:241-73.

16. Virtual AIDS Office of Hong Kong, Department of Health, Hong Kong SAR Government. Recommended clinical guidelines on the prevention of perinatal HIV transmission. 2018. Available from: https://www.aids.gov. hk/ice/ice201812.pdf. Accessed 4 Oct 2019.

17. Leung AK, Sauve RS. Breast is best for babies. J Natl Med Assoc 2005;97:1010-9.

18. Bispo S, Chikhungu L, Rollins N, Siegfried N, Newell ML. Postnatal HIV transmission in breastfed infants of HIVinfected women on ART: a systematic review and metaanalysis. J Int AIDS Soc 2017;20:21251.

19. Mendelson E, Aboudy Y, Smetana Z, Tepperberg M, Grossman Z. Laboratory assessment and diagnosis of congenital viral infections: rubella, cytomegalovirus (CMV), varicella-zoster virus (VZV), herpes simplex virus (HSV), parvovirus B19 and human immunodeficiency virus (HIV). Reprod Toxicol 2006;21:350-82.

20. Nesheim SR, Wiener J, Fitz Harris LF, Lampe MA, Weidle PJ. Brief report: estimated incidence of perinatally acquired HIV infection in the United States, 1978-2013. J Acquir Immune Defic Syndr 2017;76:461-4.

21. Peters H, Francis K, Sconza R, et al. UK mother-to-child HIV transmission rates continue to decline: 2012-2014. 
Clin Infect Dis 2017;64:527-8.

22. Narkeviciute I, Bernnatoniene J. Varicella zoster virus infection in pregnancy. In: Magel GD, Tyring SK, editors. Herpesviridae: a look into this unique family of viruses. 2012. Available from: https://www.intechopen.com/books/ herpesviridae-a-look-into-this-unique-family-of-viruses/ varicella-zoster-virus-infection-in-pregnancy. Accessed 4 Oct 2019.

23. Centre for Health Protection, Department of Health, Hong Kong SAR Government. Number of notifiable infectious diseases by month. Available from: https://www.chp.gov. hk/en/static/24012.html. Accessed 3 Oct 2019.

24. Banz K, Wagenpfeil S, Neiss A, et al. The cost-effectiveness of routine childhood varicella vaccination in Germany. Vaccine 2003;21:1256-67.

25. Fung LW, Lao TT, Suen SS, et al. Seroprevalence of varicella zoster virus among pregnant women in Hong Kong: comparison with self-reported history. Vaccine 2011;29:8186-8.

26. Ahn KH, Park YJ, Hong SC, et al. Congenital varicella syndrome: a systematic review. J Obstet Gynaecol 2016;36:563-6.

27. Hon KL, Leung TF, Cheung HM, Chan PK. Neonatal herpes: what lessons to learn. Hong Kong Med J 2012;18:602 .

28. Wilson CB, Nizet V, Maldonado Y, Remington JS, Klein JO. Remington and Klein's infectious diseases of the fetus and newborn infant. 8th ed. Philadelphia: Elsevier; 2016: 513,520-5,675,677-9,685-90,693-4,729,732.

29. Prober CG, Gershon AA, Grose C, McCracken GH Jr, Nelson JD. Consensus: varicella-zoster infections in pregnancy and the perinatal period. Pediatr Infect Dis J 1990;9:865-9.

30. Lamont RF, Sobel JD, Carrington D, et al. Varicellazoster virus (chickenpox) infection in pregnancy. BJOG 2011;118:1155-62.

31. Miller E, Cradock-Watson JE, Ridehalgh MK. Outcome in newborn babies given anti-varicella-zoster immunoglobulin after perinatal maternal infection with varicella-zoster virus. Lancet 1989;2:371-3.

32. Tan MP, Koren G. Chickenpox in pregnancy: revisited. Reprod Toxicol 2006;21:410-20.

33. Sauve RS, Leung AK. Congenital varicella syndrome with colonic atresias. Clin Pediatr (Phila) 2003;42:451-3.

34. Leung AK, Sauve RS. Colonic atresia and associated anomalies. J Paediatr Child Health 2003;39:239.

35. Mustonen K, Mustakangas P, Valanne L, Professor MH, Koskiniemi M. Congenital varicella-zoster virus infection after maternal subclinical infection: clinical and neuropathological findings. J Perinatol 2001;21:141-6.

36. Wallace MR, Bowler WA, Murray NB, Brodine SK, Oldfield EC 3rd. Treatment of adult varicella with oral acyclovir. A randomized, placebo-controlled trial. Ann Intern Med 1992;117:358-63.

37. Ogilvie MM. Antiviral prophylaxis and treatment in chickenpox. A review prepared for the UK Advisory Group on Chickenpox on behalf of the British Society for the Study of Infection. J Infect 1998;36 Suppl 1:31-8.

38. Watson B, Seward J, Yang A, et al. Postexposure effectiveness of varicella vaccine. Pediatrics 2000;105:84-8.

39. Centre for Health Protection, Department of Health, Hong Kong SAR Government. Recommendations on the use of varicella (chickenpox) vaccine in childhood immunisation programme. Available from: https://www.chp.gov.hk/files/ pdf/recommendations_on_the_use_of_varicella_vaccine_ in_cip_r.pdf. Accessed 4 Oct 2019.

40. Chan JY, Leung KM, Tam WW, Lee A. Varicella vaccine uptake and associated factors in children in Hong Kong. Epidemiol Infect 2014;142:994-1001.

41. Tam WW, Chan J, Lo KK, et al. Parental attitudes and factors associated with varicella vaccination in preschool and schoolchildren in Hong Kong: a cross-sectional study. Med (Baltimore) 2015;94:e1519.

42. Duffy MR, Chen TH, Hancock WT, et al. Zika virus outbreak on Yap Island, Federated States of Micronesia. N Engl J Med 2009;360:2536-43.

43. Musso D, Nhan T, Robin E, et al. Potential for Zika virus transmission through blood transfusion demonstrated during an outbreak in French Polynesia, November 2013 to February 2014. Euro Surveill 2014;19:1-3.

44. Prisant N, Bujan L, Benichou $\mathrm{H}$, et al. Zika virus in the female genital tract. Lancet Infect Dis 2016;16:1000-1.

45. Reynolds MR, Jones AM, Petersen EE, et al. Vital signs: update on Zika virus-associated birth defects and evaluation of all U.S. infants with congenital Zika virus exposure-U.S. Zika pregnancy registry, 2016. MMWR Morb Mortal Wkly Rep 2017;66:366-73.

46. Chan JF, Choi GK, Yip CC, Cheng VC, Yuen KY. Zika fever and congenital Zika syndrome: an unexpected emerging arboviral disease. J Infect 2016;72:507-24.

47. Pan American Health Organization, World Health Organization. Neurological syndrome, congenital malformations, and Zika virus infection. Implications for public health in the Americas. 2015: 1-8. Available from: https://www.paho.org/hq/dmdocuments/2015/2015-dec1-cha-epi-alert-zika-neuro-syndrome.pdf. Accessed 5 Oct 2019.

48. Ventura CV, Maia M, Bravo-Filho V, Góis AL, Belfort R Jr. Zika virus in Brazil and macular atrophy in a child with microcephaly. 2016;387:228.

49. Ventura CV, Maia M, Ventura BV, et al. Ophthalmological findings in infants with microcephaly and presumable intra-uterus Zika virus infection. Arq Bras Oftalmol 2016;79:1-3.

50. de Paula Freitas B, de Oliveira Dias JR, Prazeres J, et al. Ocular findings in infants with microcephaly associated with presumed Zika virus congenital infection in Salvador, Brazil. JAMA Ophthalmol 2016;134:529-35.

51. Orofino DH, Passos SR, de Oliveira RV, et al. Cardiac findings in infants with in utero exposure to Zika virus-a cross sectional study. PLoS Negl Trop Dis 2018;12:e0006362.

52. Moore CA, Staples JE, Dobyns WB, et al. Characterizing the pattern of anomalies in congenital Zika syndrome for pediatric clinicians. JAMA Pediatr 2017;171:288-95.

53. Brasil P, Pereira JP Jr, Moreira ME, et al. Zika virus infection in pregnant women in Rio de Janeiro. $\mathrm{N}$ Engl J Med 2016;375:2321-34.

54. Adebanjo T, Godfred-Cato S, Viens L, et al. Update: interim guidance for the diagnosis, evaluation, and management of infants with possible congenital Zika virus infectionUnited States, October 2017. MMWR Mork Mortal Wkly Rep 2017;66:1089-99.

55. Kuo SH, Lin LI, Chang CJ, Liu YR, Lin KS, Cheng AL. Increased risk of parvovirus B19 infection in young adult cancer patients receiving multiple courses of 
chemotherapy. J Clin Microbiol 2002;40:3909-12.

56. Lim WL, Wong KF, Lau CS. Parvovirus B19 infection in Hong Kong. J Infect 1997;35:247-9.

57. Chan PK, To KF, Yip SK, Tam JS, Cheng AF. Parvovirus B19-associated hydrops fetalis: the first confirmed case in Hong Kong. Hong Kong Med J 1998;4:321-3.

58. Ng PS, Leung TY, Leung TN, Lau TK. In utero treatment of hydrops fetalis due to parvovirus B19 infection: a case report. Hong Kong J Gynaecol Obstet Midwifery 2000;1:67-70.

59. Leung TN, Leung TY, Chan PK, Fung TY, Lau TK. Fetal parvovirus B19 infection in a twin pregnancy with 1 twin presenting with hydrops fetalis and the other asymptomatic: a case report. J Reprod Med 2007;52:41921.

60. Servey JT, Reamy BV, Hodge J. Clinical presentations of parvovirus B19 infection. Am Fam Physician 2007;75:3736.

61. Ergaz Z, Ornoy A. Parvovirus B19 in pregnancy. Reprod Toxicol 2006;21:421-35.

62. Ornoy A, Ergaz Z. Parvovirus B19 infection during pregnancy and risks to the fetus. Birth Defects Res
2017;109:311-23.

63. American College of Obstetricians and Gynaecologists. Practice Bulletin No. 151: Cytomegalovirus, parvovirus B19, varicella zoster, and toxoplasmosis in pregnancy [editorial]. Obstet Gynecol 2016;127:405.

64. Nagel HT, de Haan TR, Vandenbussche FP, Oepkes D, Walther FJ. Long-term outcome after fetal transfusion for hydrops associated with parvovirus B19 infection. Obstet Gynecol 2007;109:42-7.

65. Kinney JS, Anderson LJ, Farrar J, et al. Risk of adverse outcomes of pregnancy after human parvovirus B19 infection. J Infect Dis 1988;154:663-7.

66. Chandramouli S, Medina-Selby A, Coit D, et al. Generation of a parvovirus B19 vaccine candidate. Vaccine 2013;31:3872-8.

67. Hon KL, Leung KK. Health advice for counselling: would parvovirus infection in puppies affect children and women? N Z Med J 2020;133:129-30.

68. Centre for Health Protection, Department of Health, Hong Kong SAR Government. HIV/AIDS Surveillance Report 2015. 2016. Available from: https://www.chp.gov.hk/files/ pdf/aids15.pdf. Accessed 8 Oct 2019. 